\title{
Dilatometric and dielectric studies on phase transition of potassium dihydrogen phosphate-boric acid binary system
}

\author{
M L N MADHU MOHAN* and C HARANADH \\ Physics Department, Nagarjuna University, Nagarjunanagar 522510 , India \\ MS received 7 August 1996; revised 29 April 1997
}

\begin{abstract}
Linear thermal expansion coefficient, dielectric data and transition temperature of $\mathrm{KH}_{2} \mathrm{PO}_{4}-\mathrm{H}_{3} \mathrm{BO}_{3}$ binary are reported. The transition temperature obtained from differential scanning calorimetry (DSC) is in concurrence with the dielectric and thermal expansion data. Further, this transition is classified as first order. Thermal expansion coefficients and enthalpy values of the binary are reported and compared with the data of pure $\mathrm{KH}_{2} \mathrm{PO}_{4}$.
\end{abstract}

Keywords. Solid solution; dilatometry; thermal expansion.

\section{Introduction}

X-ray studies revealed (Hendricks 1927; Haranadh and Madhu Mohan 1992) that $\mathrm{KH}_{2} \mathrm{PO}_{4}$ and $\mathrm{KH}_{2} \mathrm{PO}_{4}-\mathrm{H}_{3} \mathrm{BO}_{3}$ solid solution belong to tetragonal system. It has been reported (William 1958) that a solid solution results when $33.7 \mathrm{~g}$ of $\mathrm{KH}_{2} \mathrm{PO}_{4}$ and $8.9 \mathrm{~g}$ of $\mathrm{H}_{3} \mathrm{BO}_{3}$ are mixed in $100 \mathrm{ml}$ of water to give a saturated solution at $302.9 \mathrm{~K}$. This binary was proposed by us (Madhu Mohan and Haranadh $1994)$ to be substitutional solid solution. In continuation of our work, we report the linear thermal expansion coefficients $(\alpha)$, dielectric data and transition temperature and enthalpy value obtained from differential scanning calorimetry (DSC) on $\mathrm{KH}_{2} \mathrm{PO}_{4}-\mathrm{H}_{3} \mathrm{BO}_{3}$ binary.

\section{Experimental}

$\mathrm{KH}_{2} \mathrm{PO}_{4}-\mathrm{H}_{3} \mathrm{BO}_{3}$ single crystals were grown from aqueous solution by slow evaporation technique. Single crystals of $\mathrm{KH}_{2} \mathrm{PO}_{4}-\mathrm{H}_{3} \mathrm{BO}_{3}$ were of $2 \times 1 \times 1 \mathrm{~mm}^{3}$ dimension. Dilatometric studies were carried out using an optical interference technique (Madhu Mohan and Harandh 1995) developed by us. The relative error in measuring the thermal expansion of a standard sample (copper) is about $0.5 \%$ of its reported value (Hahn 1970). Perkin-Elmer DSC-7 system was used for DSC data. DSC was calibrated with a standard (Indium) material. The heating rate, sample size and the sample weight were $1.5 \mathrm{~K} / \mathrm{min}, 1 \mathrm{~mm}, 7.96 \mathrm{mg}$ respectively. Dielectric work was done with an HP 4192A impedance analyser. A spring loaded sample holder was specially designed for the dielectric work. The lower plate of the dielectric cell was fixed while the upper plate could be moved with the help of a microscrew arrangement. Both the plates are guarded by a ground ring to eliminate external electrical disturbances. This holder is placed in a furnace and the temperature monitored with a thermocouple. Single cystals of $2 \times 1 \times 1 \mathrm{~mm}^{3}$ dimension were used for dielectric measurements.

\footnotetext{
*Author for correspondence
} 


\section{Results and discussion}

\subsection{Dilatometric studies}

Dilatometric studies are carried out on $\mathrm{KH}_{2} \mathrm{PO}_{4}-\mathrm{H}_{3} \mathrm{BO}_{3}$ binary, the weight fraction of $\mathrm{KH}_{2} \mathrm{PO}_{4}$ being $79 \cdot 11 \%$. Single crystals so obtained are of $2 \times 1 \times 1 \mathrm{~mm}^{3}$ dimension and are used for dilatometric work. Figures 1 and 2 illustrate the temperature dependence of $\alpha_{\mathrm{c}}$ and $\alpha_{\mathrm{a}}$ measured along two crystallographic axes in the temperature ranges $300-340 \mathrm{~K}$. An anomaly at around $310 \mathrm{~K}$ is clearly observed for $\mathrm{KH}_{2} \mathrm{PO}_{4}^{-}$ $\mathrm{H}_{3} \mathrm{BO}_{3}$ binary in both the axes indicative of a phase transition, while $\mathrm{KH}_{2} \mathrm{PO}_{4}$ does not have any such anomaly at that temperature. The reported data (Hellwedge 1975) for $\mathrm{KH}_{2} \mathrm{PO}_{4}$ for $\alpha_{\mathrm{c}}$ and $\alpha_{\mathrm{a}}$ values showed a variation from 34 to $44.4 \times 10^{-6} \mathrm{~K}^{-1}$ and 20 to $26.6 \times 10^{-6} \mathrm{~K}^{-1}$ respectively, in the temperature range $123 \mathrm{~K}-363 \mathrm{~K}$. Further our data on the pure sample of $\mathrm{KH}_{2} \mathrm{PO}_{4}$ at $305-340 \mathrm{~K}$ concur with the literature value (Hellwedge 1975) $\left(\alpha_{c}=44.4 \times 10^{-6} \mathrm{~K}^{-1}\right.$ and $\left.\alpha_{\mathrm{a}}=26.6 \times 10^{-6} \mathrm{~K}^{-1}\right)$. From figures 1 and 2 it can be observed that $\alpha_{c}$ decreases from 50 to $40 \times 10^{-6} \mathrm{~K}^{-1}$ while $\alpha_{\mathrm{a}}$ varies from 110 to $120 \times 10^{-6} \mathrm{~K}^{-1}$ respectively. Thermal expansion coefficient of $\mathrm{H}_{3} \mathrm{BO}_{3}$ along a and $\mathrm{c}$ directions are reported (Lonappan 1955) in the literature. It may be noted that the $\alpha_{\mathrm{a}}$ value of $\mathrm{H}_{3} \mathrm{BO}_{3}$ is much higher $\left(256 \times 10^{-6} \mathrm{~K}^{-1}\right)$ compared to its $\alpha_{\mathrm{c}}$ value $\left(-4 \times 10^{-6} \mathrm{~K}^{-1}\right)$. Hence the increase of thermal expansion coefficient value along $\alpha_{\mathrm{a}}$ in the binary system is justified. Further, it is interesting to note the reversal in the relative magnitudes of the axial expansion coefficients in the binary system when compared to pure $\mathrm{KH}_{2} \mathrm{PO}_{4}$ system. The reported (Lonappan 1955; Hellwedge 1975) trend in the relative magnitudes of thermal expansion coefficient values of $\mathrm{KH}_{2} \mathrm{PO}_{4}$

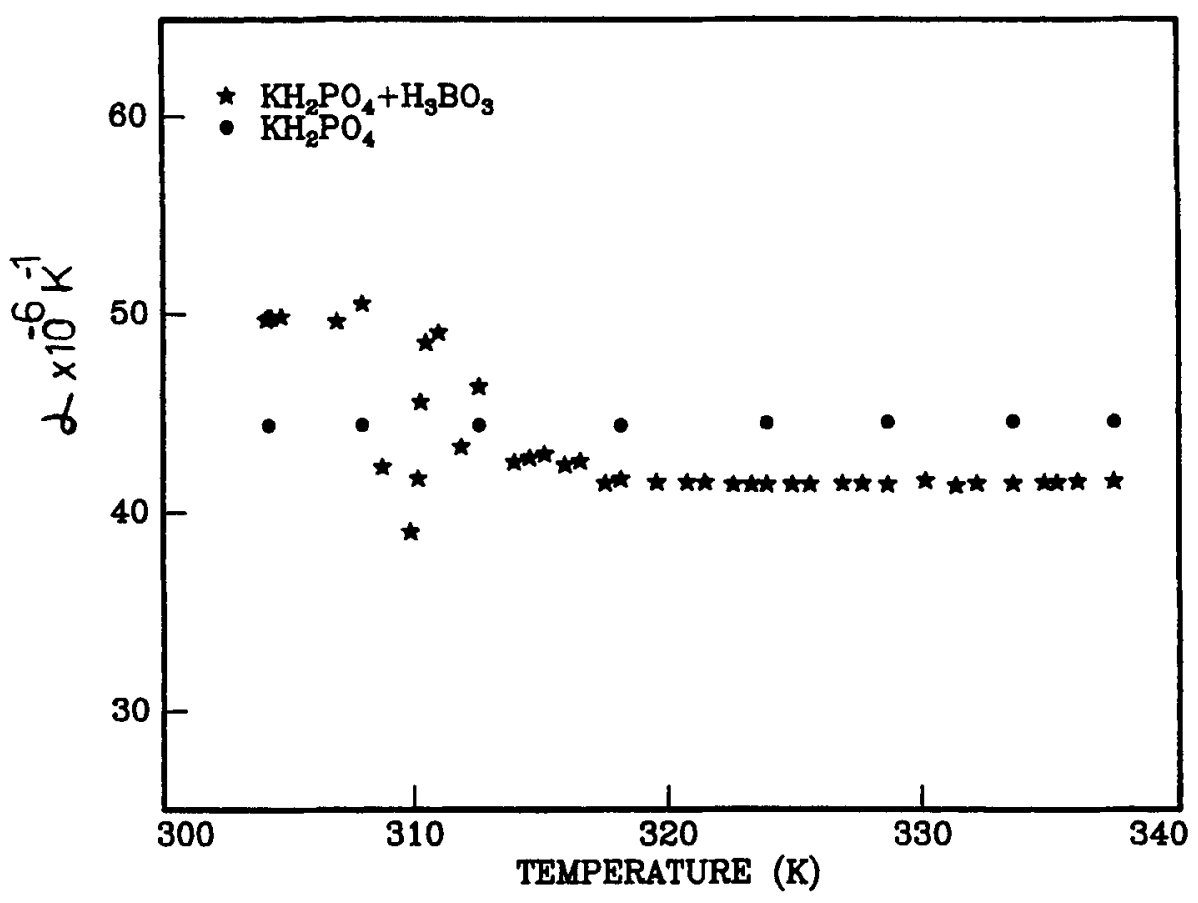

Figure 1. Thermal expansion coefficient of $\mathrm{KH}_{2} \mathrm{PO}_{4}$ and $\mathrm{KH}_{2} \mathrm{PO}_{4}-\mathrm{H}_{3} \mathrm{BO}_{3}$ along c-axis. 


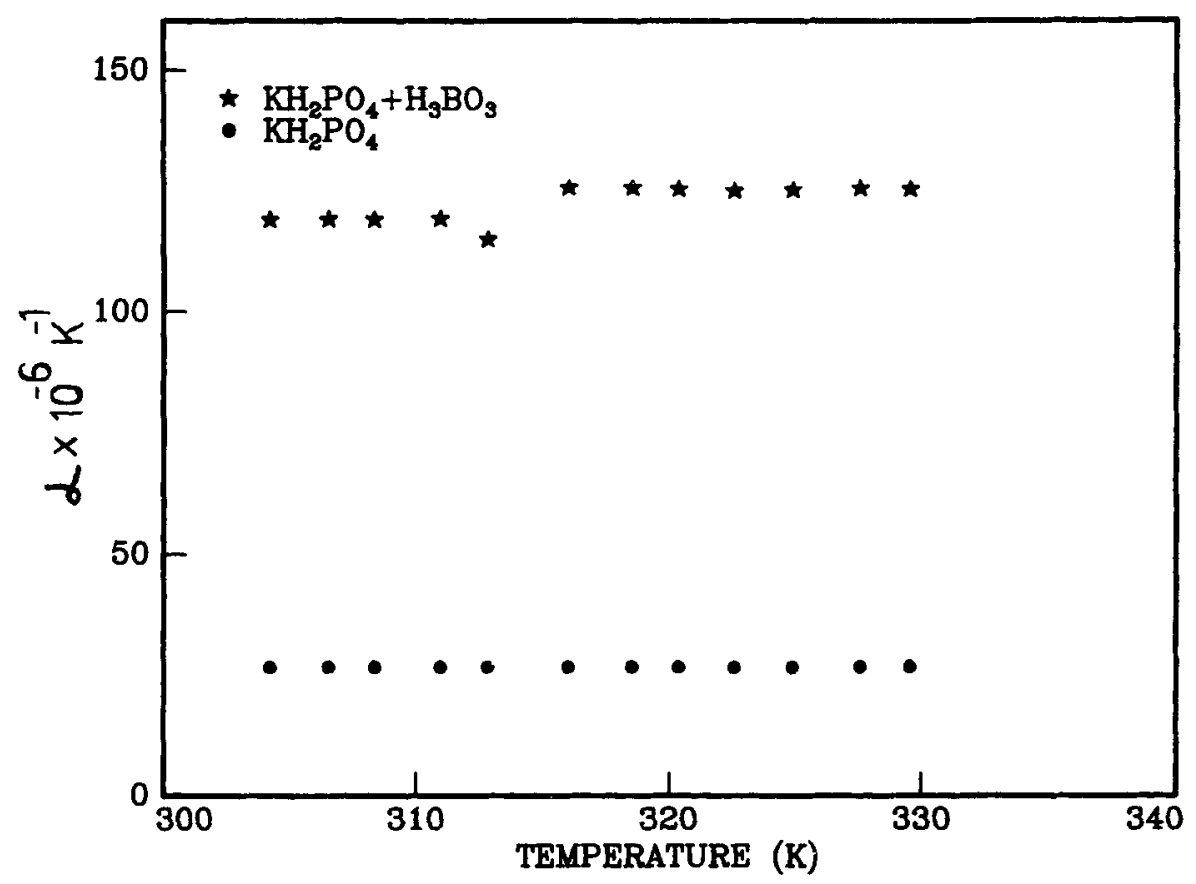

Figure 2. Thermal expansion coefficient of $\mathrm{KH}_{2} \mathrm{PO}_{4}$ and $\mathrm{KH}_{2} \mathrm{PO}_{4}-\mathrm{H}_{3} \mathrm{BO}_{3}$ along a-axis.

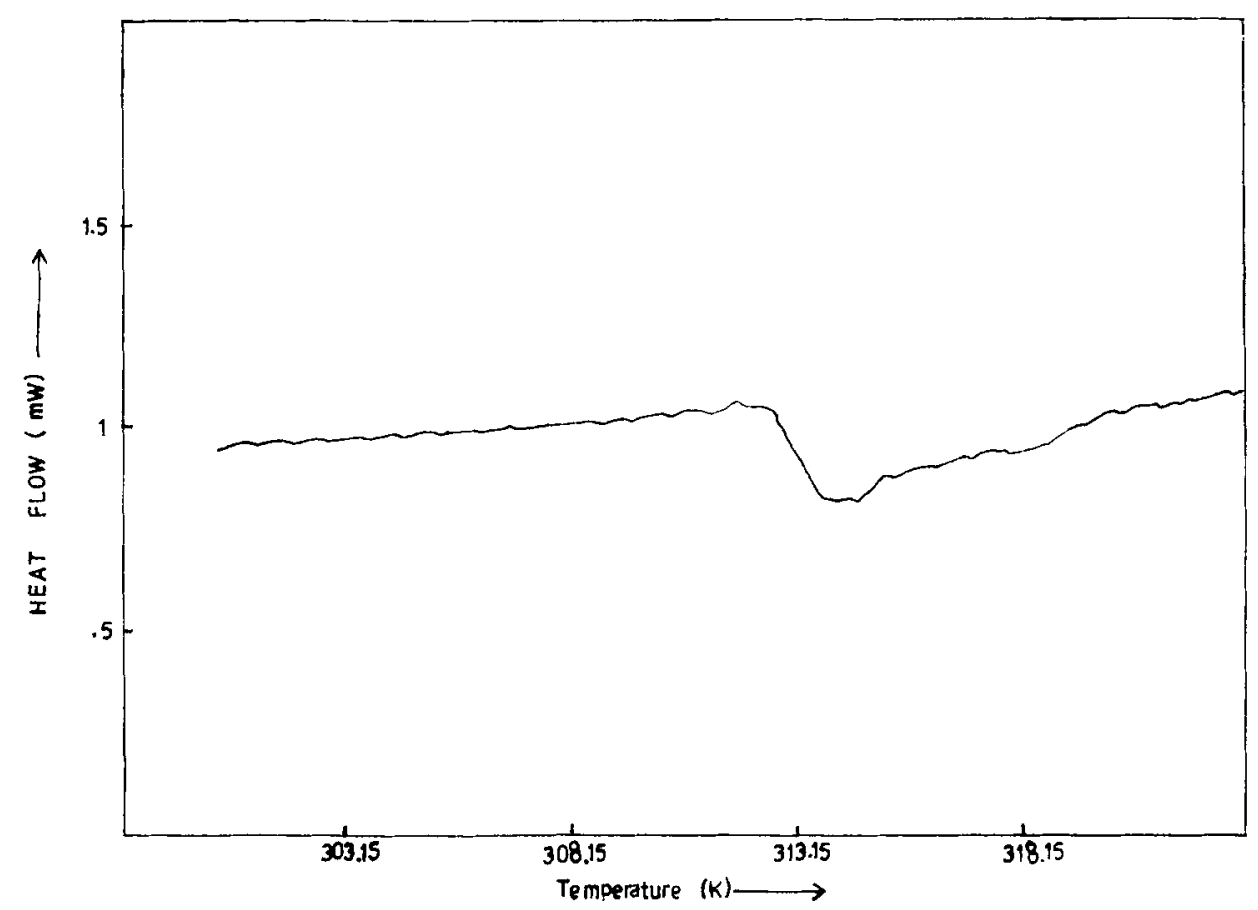

Figure 3. DSC thermogram of the binary.

and $\mathrm{H}_{3} \mathrm{BO}_{3}$ is found in good agreement with that of the binary system. Further it may be concluded from the pronounced linear thermal expansion coefficient discontinuity at the phase transition that this transition can be classified to be of first order. 
The packing index of the solid solution may explain its expansion behaviour. Packing index is defined (Fairbrain 1939) as the ratio of total volume occupied by the individual atoms to the volume of the unit cell, multiplied by a factor ten. Total volume occupied by the individual atoms can be calculated from atomic radii of the respective atoms, while the volume of the unit cell can be obtained from X-ray data. The X-ray results (Haranadh and Madhu Mohan 1992) showed that the packing index of the binary $(6.416)$, is more compared to the value of pure $\mathrm{KH}_{2} \mathrm{PO}_{4}(4.753)$. The higher value of packing index indicates that the constituent atoms in the binary are more loosely bonded than in pure $\mathrm{KH}_{2} \mathrm{PO}_{4}$. Hence, the increase in the values of $\alpha_{\mathrm{c}}$ and $\alpha_{\mathrm{a}}$ for the binary is justified.

\subsection{DSC and dielectric studies}

DSC thermogram (figure 3) of $\mathrm{KH}_{2} \mathrm{PO}_{4}-\mathrm{H}_{3} \mathrm{BO}_{3}$ binary shows a phase transition at $310 \mathrm{~K}$. The onset of the transition is at $307 \cdot 3 \mathrm{~K}$ and the offset is at $316.7 \mathrm{~K}$. The $\Delta H$ value of the binary at $310 \mathrm{~K}$ is computed to be $4.6 \mathrm{~J} / \mathrm{g} . \mathrm{KH}_{2} \mathrm{PO}_{4}$ is reported (Rapport 1966 ) to exhibit a transition at $123 \mathrm{~K}$ and its $\Delta H$ value is $1.72 \mathrm{~J} / \mathrm{g}$. From this study it has been thus observed that the addition of boric acid to $\mathrm{KH}_{2} \mathrm{PO}_{4}$ has elevated the transition temperature of the solid solution.

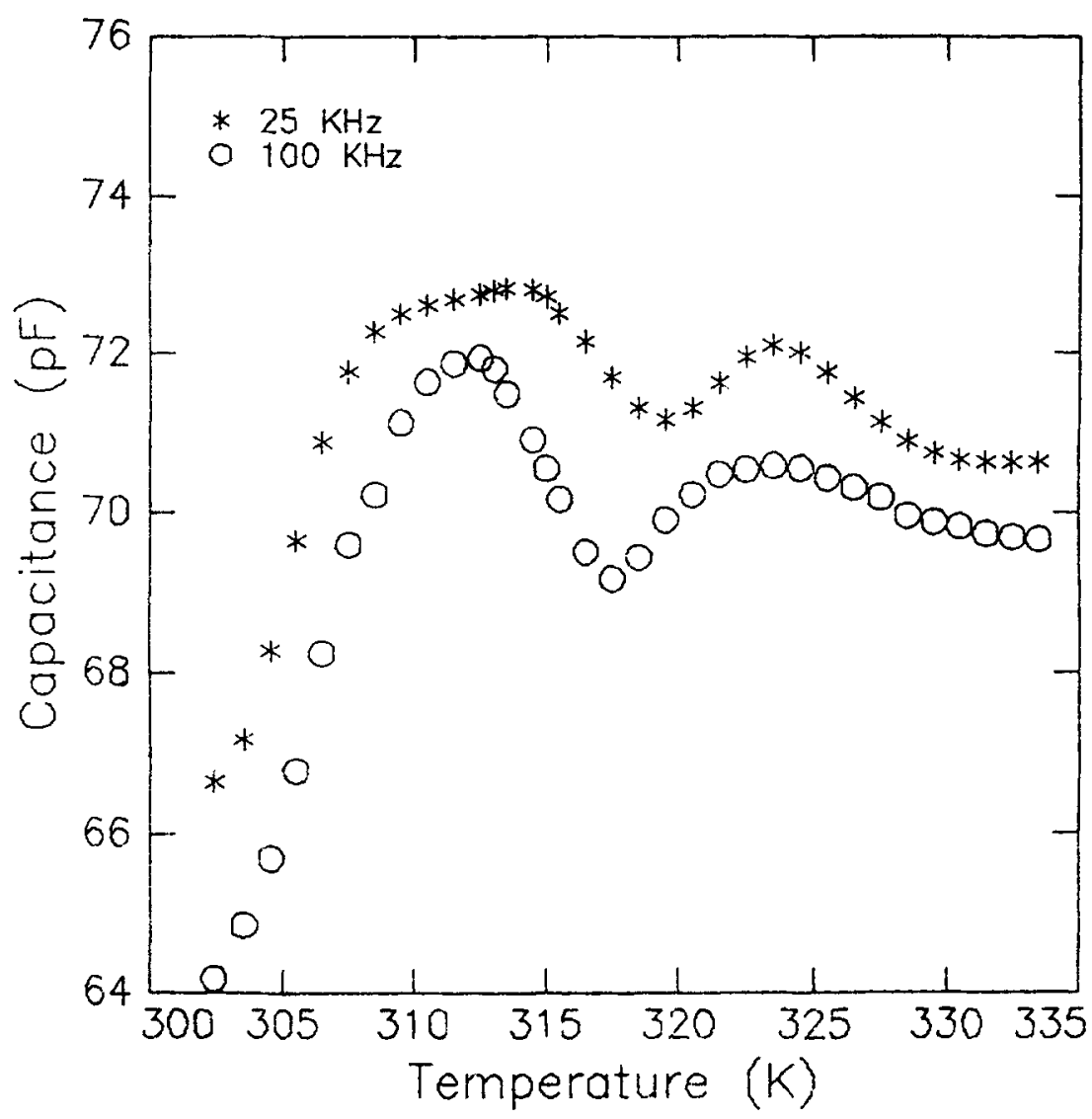

Figure 4. Temperature dependence of the capacitance at $25 \mathrm{KHz}$ and $100 \mathrm{KHz}$ of the binary. 


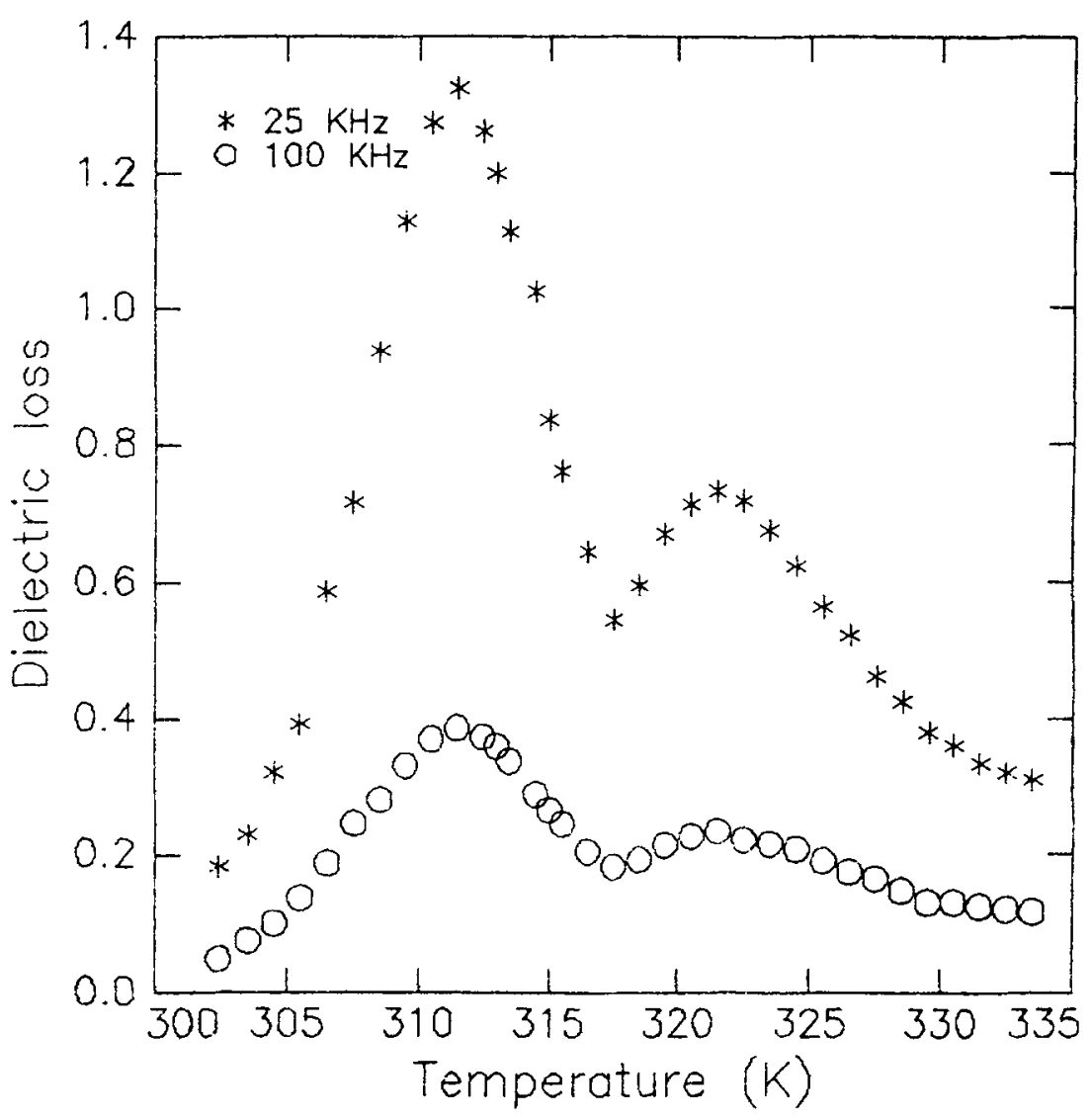

Figure 5. Temperature dependence of the dielectric loss at $25 \mathrm{KHz}$ and $100 \mathrm{KHz}$ of the binary.

Figure 4 illustrates the temperature dependence of capacitance at $25 \mathrm{KHz}$ and $100 \mathrm{KHz}$ while figure 5 shows the temperature dependence of dielectric loss at $25 \mathrm{KHz}$ and $100 \mathrm{KHz}$ respectively. Both figures 4 and 5 exhibit a discontinuity at $311 \mathrm{~K}$, further it is observed that the onset of transition temperature to be at $305 \mathrm{~K}$ and offset at $316 \mathrm{~K}$. These results are in concurrence with the dilatometric and DSC studies of the binary. The anomaly (second hump) at $322 \mathrm{~K}$ is not observable either in DSC studies or in the dilatometric studies. Even in the dielectric studies at higher frequency this anomaly is not predominant, only at $25 \mathrm{KHz}$ frequency this hump is observable. Based on these observed experimental facts it is concluded that the binary exhibits only one transition at $312 \mathrm{~K}$ and the hump at $322 \mathrm{~K}$ is more a base line correction rather than a transition.

\section{Acknowledgements}

One of the authors (MLNMM) thanks Prof. VGK M Pisipati, Director, CLCRE, Nagarjuna University for his suggestions and CSIR, New Delhi for the financial assistance. 


\section{References}

Fairbrain H W 1939 Bull. Geol. Soc. Am. 24351

Haranadh C and Madhu Mohan M L N 1992 Bull. Mater. Sci. 15385

Hendricks S B 1927 Am. J. Sci. 14269

Hellwedge K 1975 Numerical data and functional relationships in technology (New York: Springer)

Hahn A 1970 J. Appl. Phys. 415096

Lonappan M A 1955 Proc. Indian Acad. Sci. $\mathbf{4 4 2} 10$

Madhu Mohan M L N and Haranadh C 1994 Bull. Mater. Sci. 17205

Madhu Mohan M L N and Haranadh C 1995 Bull. Mater. Sci. 18599

Rapport E J 1966 J. Phys. Chem. 452721

William F L 1958 Solubilities (New Jersey: D Van Nostrand) 